\title{
Depolarization-Induced Long-Term Depression at Hippocampal Mossy Fiber-CA3 Pyramidal Neuron Synapses
}

\author{
Saobo Lei, ${ }^{1}$ Kenneth A. Pelkey, ${ }^{1}$ Lisa Topolnik, ${ }^{2}$ Patrice Congar, ${ }^{2}$ Jean-Claude Lacaille, ${ }^{2}$ and Chris J. McBain ${ }^{1}$ \\ ${ }^{1}$ Laboratory of Cellular and Synaptic Neurophysiology, National Institute of Child Health and Human Development, National Institutes of Health, Bethesda, \\ Maryland 20892, and 2Département de Physiologie, Centre de Recherche en Sciences Neurologiques, Université de Montréal, Succursale Centreville, \\ Montréal, Quebec, Canada H3C 3J7
}

Hippocampal CA3 pyramidal neurons receive two types of excitatory afferent innervation: mossy fibers (MFs) from granule cells of the dentate gyrus and recurrent collateral fibers (CFs) from other CA3 pyramidal neurons. At CF-CA3 pyramidal neuron synapses, membrane depolarization paired with low $(0.33 \mathrm{~Hz})$ presynaptic stimulation generated a heterogeneous response that ranged from long-term potentiation (LTP), long-term depression (LTD), to no alteration of synaptic strength. However, the same induction paradigm applied at MF-CA3 pyramidal neuron synapses consistently induced LTD. This novel form of LTD was independent of NMDARs, mGluRs, canna-


$\mathrm{Ca}^{2+}$ channels and release from inositol 1,4,5-trisphosphate receptor-sensitive intracellular stores. $\mathrm{Ca}^{2+}$ imaging of both proximal and distal CA3 pyramidal neuron dendrites demonstrated that the depolarizing induction paradigm differentially elevated intracellular $\mathrm{Ca}^{2+}$ levels. L-type $\mathrm{Ca}^{2+}$ channel activation was observed only at the most proximal locations where mossy fibers make synapses. Depolarization-induced LTD did not occlude the conventional $1 \mathrm{~Hz}$-induced LTD or vice versa, suggesting independent mechanisms underlie each form of plasticity. The paired-pulse ratio and coefficient of variation of synaptic transmission were unchanged after LTD induction, suggesting that the expression locus of LTD is postsynaptic. Moreover, peak-scaled nonstationary variance analysis indicated that depolarization-induced LTD correlated with a reduction in postsynaptic AMPA receptor numbers without a change in AMPA receptor conductance. Our results suggest that this novel form of LTD is selectively expressed at proximal dendritic locations closely associated with L-type $\mathrm{Ca}^{2+}$ channels.

Key words: LTD; depolarization; L-type $\mathrm{Ca}^{2+}$ channels; glutamate receptor; hippocampus; mossy fiber

\section{Introduction}

Hippocampal CA3 pyramidal neurons receive two types of excitatory innervation; the recurrent collateral fibers (CFs) from other CA3 pyramidal neurons innervate the distal dendritic portion of CA3 pyramidal neurons (CF-CA3 synapses), whereas mossy fibers (MFs) from granule cells of the dentate gyrus make synapses onto the proximal dendrites of CA3 pyramidal neurons (MF-CA3 synapses; Brown and Johnston, 1983). CF-CA3 synapses contain a high density of NMDARs (Weisskopf and Nicoll, 1995). Stimulation of CFs paired with postsynaptic depolarization of CA3 pyramidal neurons induces long-term potentiation (LTP), long-term depression (LTD), or no change in synaptic strength (Debanne et al., 1998, 1999; Montgomery et al., 2001). For such pairing-induced LTP, postsynaptic NMDAR activity leads to the conversion of silent to active synapses by the translocation of AMPA receptors (AMPARs) (Montgomery et al., 2001). Additionally, low-frequency CF stimulation induces NMDAR-

\footnotetext{
Received July 24, 2003; revised Sept. 8, 2003; accepted Sept. 9, 2003.

This work was supported by Human Frontier Science Program, National Institutes of Health, Canadian Institutes of Health Research, and Le Fonds de la Recherche en Santé de Québec.

Correspondence should be addressed to Chris J. McBain, Laboratory of Cellular and Synaptic Neurophysiology, National Institute of Child Health and Human Development, 49 Convent Drive, Bethesda, MD 20892. E-mail: mcbainc@mail.nih.gov.

Copyright $\odot 2003$ Society for Neuroscience $\quad$ 0270-6474/03/239786-10\$15.00/0
}

dependent LTD resulting from "silencing" of active synapses caused by AMPAR internalization (Montgomery and Madison, 2002). Therefore, NMDARs play an essential role in the induction of bidirectional plasticity at CF-CA3 synapses.

In contrast, the expression of NMDARs at MF-CA3 synapses is considerably lower (Monaghan and Cotman, 1985; Jonas et al., 1993; Siegel et al., 1994; Watanabe et al., 1998; Weisskopf and Nicoll, 1995). The ratio of NMDAR- to AMPAR-mediated EPSCs at MF-CA3 synapses is 30\% of that found at CF-CA3 synapses (Weisskopf and Nicoll, 1995). Furthermore, unlike CF inputs to CA3 pyramids, both high-frequency stimulation-induced LTP (Harris and Cotman, 1986; Zalutsky and Nicoll, 1990; Xiang et al., 1994; Nicoll and Malenka, 1995; Lopez-Garcia et al., 1996; Castillo et al., 1997; Yeckel et al., 1999; Mellor and Nicoll, 2001) and low-frequency-induced LTD (Kobayashi et al., 1996; Tzounopoulos et al., 1998) at MF-CA3 synapses are NMDAR-independent.

In addition to the differences in NMDAR expression and mechanisms of synaptic plasticity, the distribution of voltagedependent $\mathrm{Ca}^{2+}$ channels (VGCCs), particularly L-type $\mathrm{Ca}^{2+}$ channels, is also distinct between $\mathrm{CF}-\mathrm{CA} 3$ and $\mathrm{MF}-\mathrm{CA} 3$ synaptic locations. L-type $\mathrm{Ca}^{2+}$ channels selectively localize to the somata and proximal dendrites of CA3 pyramidal neurons (Westenbroek et al., 1990; Hell et al., 1993; Elliott et al., 1995) where MFs 
arrive (Brown and Johnston, 1983), whereas $\mathrm{N}$ - and P/Q-type $\mathrm{Ca}^{2+}$ channels localize to distal dendrites of CA3 pyramidal neurons (Elliott et al., 1995) where CFs make contact. This selective distribution of VGCCs implies differing roles for these channels at each synapse type.

In the present study, we describe a role for L-type $\mathrm{Ca}^{2+}$ channels in a novel type of LTD induced by postsynaptic membrane depolarization at MF-CA3 synapses. The depolarizationinduced LTD does not require activation of NMDARs, mGluRs, cannabinoid, or opioid receptors but is dependent on an elevation of postsynaptic $\mathrm{Ca}^{2+}$ through L-type $\mathrm{Ca}^{2+}$ channels and release from intracellular stores. Peak-scaled variance analysis shows that this novel form of LTD is not caused by a change in AMPAR conductance, but rather a reduction in the number of postsynaptic AMPARs.

\section{Materials and Methods}

Hippocampal slice preparation. Transverse hippocampal slices $(300 \mu \mathrm{m})$ were typically obtained from 15- to 16-d-old Sprague Dawley rats as described previously (Lei and McBain, 2002, 2003). In experiments examining developmental regulation of LTD, we extended our experiments to 10-d-old and >35-d-old animals. Rats were deeply anesthetized with isoflurane, and the brain was dissected out in ice-cold saline solution that contained (in mM): $130 \mathrm{NaCl}, 24 \mathrm{NaHCO}_{3}, 3.5 \mathrm{KCl}, 1.25 \mathrm{NaH}_{2} \mathrm{PO}_{4}, 0.5$ $\mathrm{CaCl}_{2}, 5.0 \mathrm{MgCl}_{2}$, and 10 glucose, saturated with $95 \% \mathrm{O}_{2}$ and $5 \% \mathrm{CO}_{2}$, $\mathrm{pH}$ 7.4. Slices were initially incubated in the above solution at $35^{\circ} \mathrm{C}$ for 40 min for recovery and then kept at room temperature until use. All animal procedures conformed to the National Institutes of Health animal welfare guidelines.

Whole-cell recordings. Whole-cell patch-clamp recordings using an Axopatch $200 \mathrm{~A}$ or $700 \mathrm{~A}$ amplifier (Axon Instruments, Foster City, CA) in voltage-clamp mode were made from CA3 pyramidal neurons, visually identified with infrared video microscopy and differential interference contrast optics. Unless stated otherwise, recording electrodes were filled with the following (in mM): 100 Cs-gluconate, $0.6 \mathrm{EGTA}, 5 \mathrm{MgCl}_{2}$, $8 \mathrm{NaCl}, 2 \mathrm{ATP}_{2} \mathrm{Na}$, 0.3 GTPNa, 40 HEPES, and 1 QX-314, pH 7.2-7.3. The extracellular solution comprised (in mM): $130 \mathrm{NaCl}, 24 \mathrm{NaHCO}_{3}$, $3.5 \mathrm{KCl}, 1.25 \mathrm{NaHPO}_{4}, 2.5 \mathrm{CaCl}_{2}, 1.5 \mathrm{MgCl}_{2}, 10$ glucose, and $0.01 \mathrm{bicu}-$ culline methobromide, saturated with $95 \% \mathrm{O}_{2}$ and $5 \% \mathrm{CO}_{2}, \mathrm{pH} 7.4$. Unless stated otherwise, recordings were made at room temperature $\left(\sim 24^{\circ} \mathrm{C}\right)$ with cells held at $-60 \mathrm{mV}$. Series resistance was rigorously monitored by the delivery of $5 \mathrm{mV}$ voltage steps after each evoked current. Experiments were discontinued if the series resistance changed by $>10 \%$. Synaptic responses were evoked at $0.33 \mathrm{~Hz}$ by low-intensity stimulation (80-100 $\mu \mathrm{sec}$ duration; $40-80 \mu \mathrm{A}$ intensity) via a constantcurrent isolation unit (A360; World Precision Instruments, Sarasota, FL) connected to a patch electrode filled with oxygenated extracellular solution. Mossy fibers or recurrent collateral fibers were stimulated by placing a stimulation electrode in stratum lucidum or stratum radiatum, respectively. Mossy fiber stimulation was initially identified by the shape of the evoked EPSCs, which usually had a briefer rise time (Yeckel et al., 1999; Henze et al., 2000) and finally confirmed by perfusion of $\left(2 S, 2^{\prime} \mathrm{R}\right.$, $\left.3^{\prime} \mathrm{R}\right)-2-\left(2^{\prime}, 3^{\prime}\right.$-Dicarboxycyclopropyl)glycine (DCG-IV, $\left.1 \mu \mathrm{M}\right)$ at the end of each experiment (Toth et al., 2000). To exclude the possible contamination from fibers other than mossy fibers, only data from those cells that display $>80 \%$ inhibition by DCG-IV was included for analysis.

$\mathrm{Ca}^{2+}$-imaging of pyramidal cell dendrites. Combined whole-cell voltage-clamp recordings and confocal calcium imaging were performed using an Axopatch 200B amplifier and a multiphoton confocal laser scanning microscope LSM 510 (Carl Zeiss, Kirkland, Quebec, Canada) equipped with a $40 \times$ long-range water-immersion objective (numerical aperture 0.8) (Bertrand et al., 2001). Recording pipettes (4-5 M 2 ) were filled with a solution containing (in mM): $130 \mathrm{CsMeSO}_{3}, 5 \mathrm{CsCl}, 2 \mathrm{MgCl}_{2}$, 5 diNa-phosphocreatine, 0.5 EGTA, 10 HEPES, $2 \mathrm{ATP}_{2} \mathrm{Na}, 0.4 \mathrm{GTPNa}$, 0.4 spermine, 1 QX314, and 0.2 Oregon Green-488-BAPTA-I hexapotassium salt (OGB1) ( $\mathrm{pH} 7.2-7.3,285 \mathrm{mOsm})$. After obtaining the wholecell configuration, $20-30 \mathrm{~min}$ were allowed for intracellular diffusion of the fluorophore, and two apical dendritic regions were selected for measurements (proximal 25-75 $\mu \mathrm{m}$ from the soma; distal 100-150 $\mu \mathrm{m}$ from the soma). Two-photon confocal imaging was performed using a tunable Ti:Sapphire laser mode-locked at $780 \mathrm{~nm}$ pumped by a solid state source (Mira 900 and 5 W Verdi argon-ion laser; Coherent, Santa Clara, CA). Emission was detected through a long-pass filter (cutoff $505 \mathrm{~nm}$ ), and images were acquired and analyzed using the LSM 510software (Carl Zeiss). Fluorescence signals were collected by scanning the two regions of interest (ROIs) $(\sim 5 \times 10 \mu \mathrm{m})$; each scan consisted of a series of 10 images $(\sim 200 \mathrm{msec} /$ image $)$. ROIs fluorescence images were collected every minute during $5 \mathrm{~min}$ epochs at the holding potential $\left(V_{\mathrm{H}}\right)$ of -60 $\mathrm{mV}$, at $V_{\mathrm{H}}=-10 \mathrm{mV}$ and finally back to $V_{\mathrm{H}}=-60 \mathrm{mV}$. The image focus of ROIs was carefully checked and occasionally adjusted for possible drift. For analysis, the background (measured in a similar region outside the cell) was subtracted from the fluorescence intensity averaged over the ROI. Changes in fluorescence were calculated relative to the baseline and expressed as $\% \Delta F / F=\left[\left(F-F_{\text {rest }}\right) / F_{\text {rest }}\right] \times 100$. The averaged baseline fluorescence before depolarization $\left(F_{\text {rest }}\right)$ was determined over the $5 \mathrm{~min}$ control period at $V_{\mathrm{H}}-60 \mathrm{mV}$. The peak calcium transient was calculated after the onset of the depolarizing step to $-10 \mathrm{mV}$. Summary data are expressed as mean \pm SE. Statistical significance $(p<0.05)$ was determined using an ANOVA in Igor Pro (Wavemetrics, Lake Oswego, OR).

Peak-scaled nonstationary variance analysis. Peak-scaled nonstationary variance analysis was used to estimate the conductance and numbers of synaptic AMPARs (Traynelis et al., 1993; Traynelis and Jaramillo, 1998; Benke et al., 1998; Lei and McBain, 2002) before and after the induction of LTD. The recorded AMPAR EPSCs were initially inspected visually to exclude those responses contaminated with spontaneous synaptic activity. Only those traces showing fast rise time and smooth decay were selected for analysis. The selected EPSCs were aligned and averaged. The average response was scaled to the peak and subtracted from individual responses to compute the variance. A period of 0-87 msec commencing at the EPSC peak was selected for analysis. The average EPSC response was then divided into 100 equally sized bins and the corresponding variances pooled. The binned variance was plotted against the mean current amplitude, and the single-channel current and the number of AMPARs were estimated by fitting the data according to the following equation: $\sigma^{2}=i I-I^{2} / N+\sigma_{\text {base }}$, where $\sigma^{2}$ is the variance, $I$ is the mean current, $N$ is the number of open channels, $i$ is the single-channel current, and $\sigma_{\text {base }}$ is the background variance. The single-channel conductance was measured by $\gamma=i /\left(E-E_{\mathrm{rev}}\right)$, where $E$ is the holding potential, and $E_{\mathrm{rev}}$ is the reversal potential that was measured to be close to $0 \mathrm{mV}$ under our recording conditions.

Data analysis. Data are presented as means \pm SEM. Student's $t$ tests and ANOVA were used for statistical analysis as appropriate; $p$ values are reported throughout the text. Coefficient of variation (CV) (SD/mean) was calculated from sequential 20 evoked EPSCs.

Chemicals. DCG-IV, $( \pm)$-amino-4-carboxy-methyl-phenylacetic acid (MCPG), and naloxone were products of Tocris (Ellisville, MO). All other compounds were purchased from Sigma-Aldrich (St. Louis, MO). Nifedipine was initially dissolved in DMSO at a stock concentration of 50 $\mathrm{mm}$ and then diluted in the external solution to a final concentration of $20 \mu \mathrm{M}$. Because nifedipine is light-sensitive, the solution was prepared immediately before use and applied to cells in a light protected manner.

\section{Results}

\section{Heterogeneity of responses evoked by membrane} depolarization at CF-CA3 and MF-CA3 synapses

CA3 pyramidal neurons are innervated by both MFs and recurrent CFs. Because of the distinct distribution of NMDARs and VGCCs at MF-CA3 and CF-CA3 synapses, we initially examined the synaptic responses at both synapses using a protocol consisting of postsynaptic membrane depolarization from -60 to -10 $\mathrm{mV}$ for $5 \mathrm{~min}$ without changing the presynaptic stimulation frequency $(0.33 \mathrm{~Hz})$. This "pairing paradigm" should permit activation of both NMDARs and VGCCs, in particular L-type $\mathrm{Ca}^{2+}$ channels. At CF-CA3 synapses the pairing protocol induced a 
A

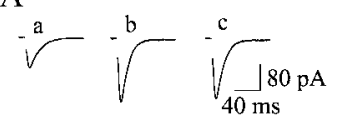

B
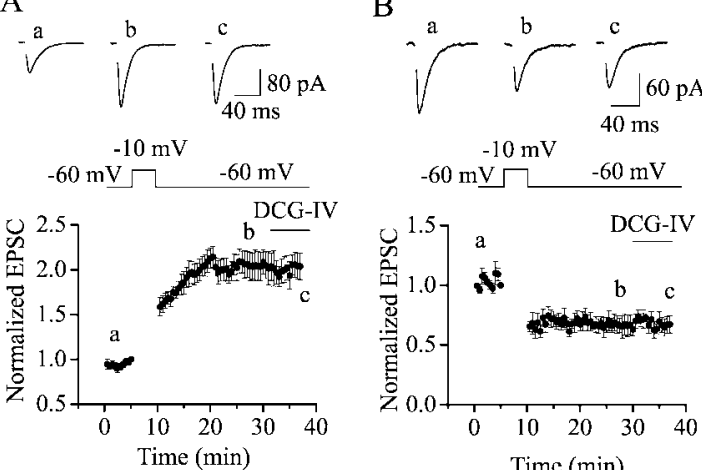

C
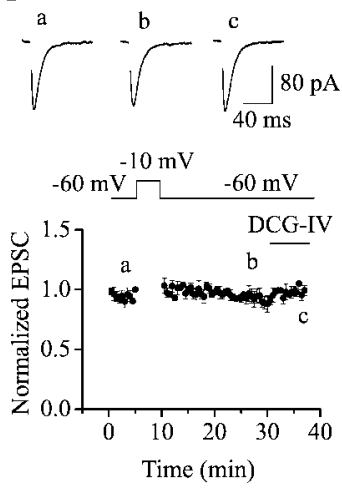



$\mathrm{D}$
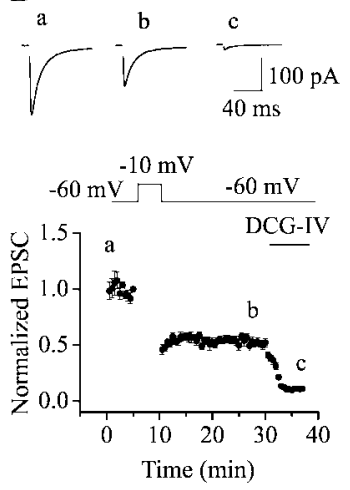

Figure 1. Membrane depolarization paired with presynaptic stimulation induces a heterogeneous response at CF-CA3 synapses but consistent LTD at MF-CA3 synapses. $A$, Depolarization from -60 to $-10 \mathrm{mV}$ for $5 \mathrm{~min}$ without changing the stimulation frequency $(0.33 \mathrm{~Hz})$ induced LTP at 6 of 15 CF-CA3 synapses. Insensitivity of the EPSCs to DCG-IV (1 $\mu \mathrm{M})$ confirms that the inputs were not from mossy fibers but from recurrent collateral fibers. Top panel shows the EPSCs recorded at different times in the figure. Stimulation artifacts were blanked. $B$, The same paradigm induced LTD at five CF-CA3 synapses. C, Four of the 15 CF-CA3 synapses showed no apparent change in synaptic strength. D, Averaged LTD induced by the paradigm at $12 \mathrm{MF}-\mathrm{CA} 3$ synapses. EPSCs were significantly inhibited by DCG-IV, demonstrating that the afferent fibers were mossy fiber in origin.

heterogeneous response; of the 15 synaptic responses examined, six synapses displayed LTP $(202.4 \pm 14.4 \%$ of control $15 \mathrm{~min}$ after induction protocol; $p=0.0008$ ) (Fig. 1A), five synapses exhibited LTD $(67.0 \pm 6.3 \%$ of control; $p=0.006)$ (Fig. $1 B$ ), and four synapses did not show an appreciable change in EPSC amplitude $(92.7 \pm 3.3 \% ; p=0.12$ ) (Fig. $1 C)$. These results are consistent with previous findings (Debanne et al., 1998, 1999; Montgomery et al., 2001), demonstrating a similar heterogeneity in response to a similar pairing protocol. In contrast, the same paradigm consistently induced LTD at MF-CA3 synapses with EPSC amplitudes reduced to $49.9 \pm 4.5 \%$ of $\operatorname{control}(n=12 ; p=0.002)$ $15 \mathrm{~min}$ after the induction protocol (Fig. $1 D)$. The reduction in EPSC amplitude was typically evident after return of membrane potential to $-60 \mathrm{mV}$ after depolarization but occasionally manifested as a gradual decline during the first $5 \mathrm{~min}$ after the induction protocol.

Because mossy fibers do not fully mature until the end of the third postnatal week (Amaral and Dent, 1981) and another plasticity inducing paradigm $(100 \mathrm{~Hz}$ for $1 \mathrm{sec}$ ) elicits LTP in adult rats (Yeckel et al., 1999), but LTD in juvenile rats (Domenici et al., 1998), we examined the potential developmental regulation of LTD induced by the present pairing paradigm by including three additional age groups. Although the pairing protocol induced the same magnitude of LTD in slices from 10-d-old rats $(45.5 \pm 4.2 \%$ of control; $n=5 ; p=0.49$; compared with the LTD

from 15- to 16-d-old rats; data not shown) LTD was significantly reduced in slices from 21 -d-old animals $(83.2 \pm 5.6 \%$ of control; $n=5 ; p=0.003$; compared with the LTD from 15- to 16 -d-old) and could not be observed in slices prepared from rats $>35$-d-old (95.7 $\pm 8.9 \%$ of control; $n=6 ; p=0.65)$. These results indicate that the observed LTD is developmentally regulated and restricted to juvenile rats. Thus, to facilitate further investigation of this novel LTD, all subsequent experiments were conducted on 15- to 16-d-old rats.

\section{LTD is independent of NMDARs, mGluRs, cannabinoid receptors, or coincident synaptic activity, but requires an elevation of postsynaptic $\mathrm{Ca}^{2+}$}

A major consequence of membrane depolarization that has been linked to synaptic plasticity is the relief of voltage-dependent $\mathrm{Mg}^{2+}$ block of NMDARs. To examine whether NMDAR activity plays a role in the presently observed LTD we attempted to induce LTD while NMDARs were blocked. In the presence of the NMDAR antagonist D,L-APV $(100 \mu \mathrm{M})$ EPSC amplitudes were reduced to $45.1 \pm 4.9 \%$ of control $(n=6 ; p=0.0001) 15 \mathrm{~min}$ after the postsynaptic depolarization induction protocol (Fig. $2 A, E$ ). The magnitude of LTD achieved in D,L-APV was not significantly different from that in the absence of NMDAR block (Fig. 2A,E), suggesting that NMDAR activity is not required for the novel LTD at MF-CA3 synapses. In addition to NMDARs, the metabotropic class of glutamate receptors has been implicated in plasticity at a variety of synapses (Bortolotto et al., 1999; Cho and Bahir, 2002). Of particular relevance, group II mGluRs play a prominent role in the development of low-frequency stimulation ( $1 \mathrm{~Hz}$ for $15 \mathrm{~min}$ ) induced LTD at MF-CA3 connections, which is expressed presynaptically as a depression in transmitter release (Tzounopoulos et al., 1998). However, in the presence of the broad spectrum, nonselective group I/II mGluR antagonist MCPG (1 mM), EPSC amplitudes were still reduced to $45.3 \pm$ $3.1 \%$ of control $(n=5 ; p=0.00006)$ after 5 min of postsynaptic depolarization (Fig. $2 B, E$ ). Again the magnitude of LTD achieved in the presence of MCPG was not significantly different from control (Fig. $2 E$ ), excluding a role for mGluRs in depolarizationinduced LTD, thus further distinguishing it from previously reported forms of LTD at MF-CA3 synapses. The lack of requirement for NMDAR and mGluR activity to induce LTD suggested that glutamate release may not be required. To determine whether synaptic activity coincident with postsynaptic membrane depolarization is required for MF-CA3 LTD, we recorded basal EPSCs then depolarized CA3 neurons for 5 min without presynaptic stimulation, only resuming stimulation after return of the membrane potential to $-60 \mathrm{mV}$. Using this paradigm depolarization from -60 to $-10 \mathrm{mV}$ alone was found to reduce EPSC amplitudes to the same level $(48.1 \pm 4.9 \%$ of control; $n=$ $5 ; p=0.0005$ ) (Fig. 2C,E), suggesting that coincident synaptic activity is not required to induce LTD at MF-CA3 synapses. We therefore will subsequently refer to this novel form of LTD as “depolarization-induced LTD”.

Because LTD induction occurred in the absence of presynaptic stimulation, we next tested whether depolarization-induced LTD could influence multiple MF-CA3 synapses onto a single neuron by placing two stimulation electrodes in different locations of stratum lucidum to stimulate two distinct MF inputs (Fig. 3A). To ensure that each stimulating electrode activated a different MF input, we first recorded EPSCs evoked by sequentially stimulating the two inputs at $50 \mathrm{msec}$ intervals. If common fibers are stimulated, the amplitude of the second EPSC should be larger than the amplitude of the EPSC evoked by the second 
A

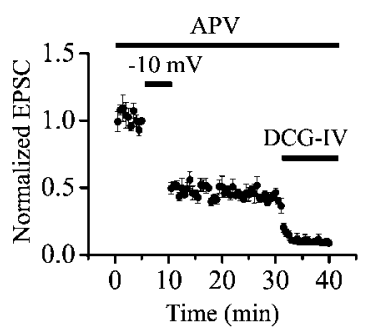

$\mathrm{C}$

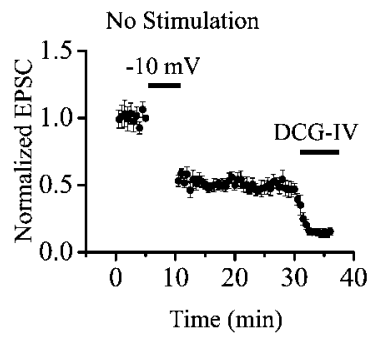

$\mathrm{E}$



Figure 2. Depolarization-induced LTD is independent of NMDARs, mGluRs, or coincident synaptic activity but relies on postsynaptic $\mathrm{Ca}^{2+}$ elevation. $A$, Bath application of $\mathrm{D}, \mathrm{L}-\mathrm{APV}(100$ $\mu \mathrm{M}$ ) did not block the induction of LTD induced by the pairing paradigm. $B$, Bath application of MCPG (1 mM) failed to block LTD induction. C, LTD induction is independent of coincident presynaptic stimulation. After recording basal EPSCs at $0.33 \mathrm{~Hz}$, presynaptic stimulation was stopped, and the postsynaptic membrane was depolarized from -60 to $-10 \mathrm{mV}$ for $5 \mathrm{~min}$, and stimulation was resumed to record EPSCs; membrane depolarization alone induced LTD.D, Intracellular dialysis of BAPTA ( $30 \mathrm{~mm}$ ) blocked the membrane depolarization-induced LTD. E, Summary bar graph directly comparing the magnitude of depolarization-induced LTD under the conditions indicated. Values are the average EPSC amplitudes recorded at 15 or 20 min after depolarization protocol expressed as a percentage of control values obtained just before initiating the depolarization protocol ${ }^{* *} p<0.01$ compared with control LTD).

electrode in isolation because of the strong paired-pulse facilitation present at MF-CA3 synapses (Toth et al., 2000). Having ensured that two different MF inputs were being stimulated, we investigated the expression of depolarization-induced LTD at the two distinct MF-CA3 synapses on a single neuron. Depolarization without presynaptic stimulation for $5 \mathrm{~min}$ induced LTD at both MF inputs (Fig. 3B,C); EPSC amplitudes were depressed to $52.8 \pm 3.6 \%(n=5)$ and $56.1 \pm 5.6 \%(n=5)$ of control, respectively (Fig. $3 D$ ). Because these results suggest that depolarizationinduced LTD is expressed heterosynaptically among MF inputs, we also examined whether depolarization-induced LTD occurred at both mossy fiber and CA3 collateral inputs onto single CA3
A

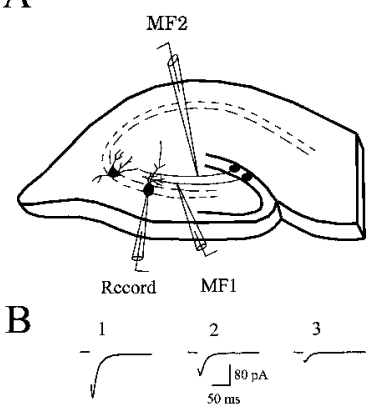

E

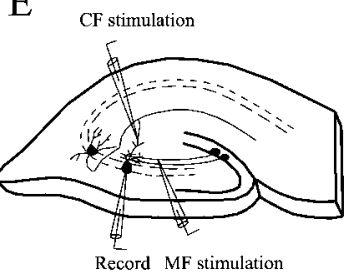

$\mathrm{F}$


C
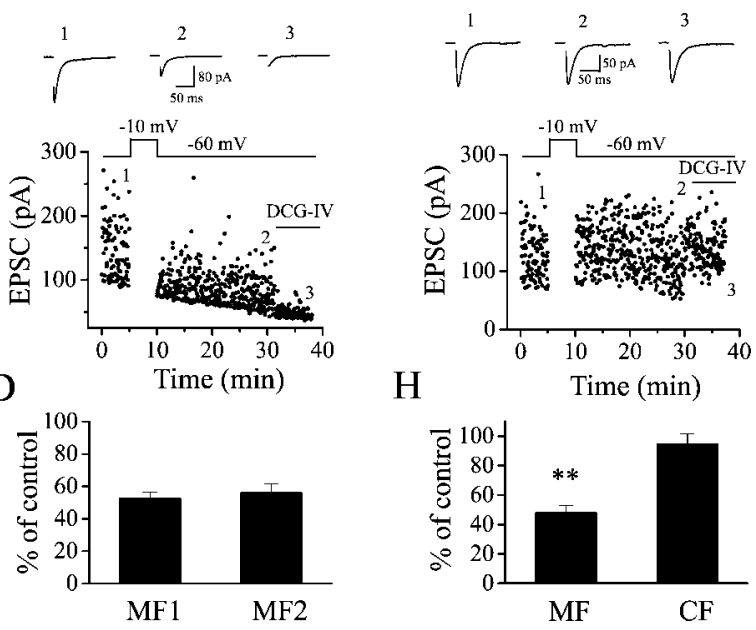

Figure 3. $A-D$, Membrane depolarization induces LTD at two distinct MF-CA3 synapses recorded from single CA3 pyramidal neurons. $A$, Schematic illustration of experimental arrangement. Two different MF inputs were stimulated by placing two stimulation electrodes in different locations within the stratum lucidum. EPSCs generated by alternative stimulation of two MF inputs were recorded from a single CA3 pyramidal neuron. After recording basal EPSCs at -60 $\mathrm{mV}$, stimulations of both MF inputs were discontinued, and CA3 neuron was depolarized to $-10 \mathrm{mV}$ for $5 \mathrm{~min}$. Stimulation was resumed to record EPSCs after membrane depolarization. Membrane depolarization produces $L T D$ at both MF-CA3 synapses $(B, C)$ in a single pyramidal neuron. $D$, Summarized data from five cells $(* * p<0.01$; EPSC amplitude at 20 min after depolarization protocol). $E-H$, Membrane depolarization induces LTD at MF-CA3 synapses without changing the synaptic strength at $C F-C A 3$ synapses recorded from single CA3 pyramidal neuron. E, Schematic illustration of experimental arrangement. MF and CF were stimulated by placing one electrode in stratum lucidum (MF stimulation) and one in stratum radiatum (CF stimulation), respectively. EPSCs generated by alternative stimulation of MF and CF were recorded from a single CA3 pyramidal neuron. After recording basal EPSCs at $-60 \mathrm{mV}$, stimulation of both MF and CF were discontinued, and the CA3 neuron was depolarized to $-10 \mathrm{mV}$ for $5 \mathrm{~min}$. Stimulation was resumed to record EPSCs after membrane depolarization. Membrane depolarization produces LTD at MF-CA3 synapse $(F)$ without changing synaptic strength at CF-CA3 synapse ( $G$ ) in a single pyramidal neuron. $H$, Summarized data from five cells $s{ }^{* *} p<$ 0.01 , EPSC amplitude at 20 min after depolarization protocol).

pyramidal neurons by alternatively stimulating the mossy fibers and the recurrent collateral fibers (Fig. $3 E$ ). After recording basal EPSCs at both MF-CA3 and CF-CA3 synapses, we depolarized CA3 pyramidal neurons from -60 to $-10 \mathrm{mV}$ without stimulation of either mossy fibers or recurrent collateral fibers for $5 \mathrm{~min}$. In a single neuron, depolarization produced LTD at MF-CA3 synapses (Fig. $3 F$ ) without altering the synaptic strength at $\mathrm{CF}-$ 
CA3 synapse (Fig. 3G). Overall, depolarization depressed EPSCs to $48.1 \pm 4.8 \%$ of control $(n=5 ; p=0.0004)$ at MF-CA3 synapses and to $94.6 \pm 6.9 \%$ of $\operatorname{control}(n=5 ; p=0.47)$ at CF-CA3 synapses (Fig. $3 H$ ). These results suggest that the heterosynaptic expression of depolarization-induced LTD is restricted to MFCA3 synapses.

Whereas LTD was reliably induced by 5 min postsynaptic depolarization, we also examined the level of LTD produced by varying the duration of the membrane depolarization. Postsynaptic depolarization for 1 or 3 min induced significantly less LTD ( 1 min: $93.1 \pm 4.6 \%, n=5, p=0.21 ; 3 \mathrm{~min}: 71.3 \pm 2.6 \%, n=5$, $p=0.03$ of control), whereas, depolarization for $10 \mathrm{~min}$ did not further increase the level of LTD $(48.2 \pm 3.5 \%, n=4, p=0.78)$ compared with LTD induced by 5 min depolarization. Additionally, because various aspects of synaptic transmission, such as transmitter uptake and failure rate, can be influenced by temperature (Bergles and Jahr, 1998; Hardingham and Larkman, 1998; Auger and Attwell, 2000; Gasparini et al., 2000), we were concerned whether depolarization induced LTD occurred at a more physiologically relevant temperature. However, when recordings were performed at $30-34^{\circ} \mathrm{C}\left(31 \pm 1^{\circ} \mathrm{C}\right)$, postsynaptic depolarization for $5 \mathrm{~min}$ induced LTD similar to that observed at room temperature: 20 min after the induction protocol EPSC amplitudes were reduced to $54 \pm 9.7 \%$ of control responses obtained before depolarization ( $n=7 ; p=0.004$ ) (Fig. $2 E$ ). Thus, depolarization-induced LTD is not temperature-dependent and can be saturated with 5 min of depolarization.

In many cells, postsynaptic depolarization can potentially release endogenous cannabinoids, which translocate to the presynaptic domain to transiently inhibit transmitter release (for review, see Alger, 2002). Moreover, cannabinoids are implicated in both LTP (Misner and Sullivan, 1999; Carlson et al., 2002) and LTD (Gerdeman et al., 2002; Chevaleyre and Castillo, 2003). We therefore examined the potential involvement of cannabinoids in depolarization-induced LTD. In slices pretreated and perfused with the CB1 receptor antagonist AM-251 (10 $\mu \mathrm{M})$, depolarization still induced LTD (47.2 $\pm 4.2 \%$ of control 15 min after induction protocol; $n=5 ; p=0.005$ ) (Fig. $2 E$ ), demonstrating that release of cannabinoids, if any, is not involved in depolarization-induced LTD at MF-CA3 synapses. We also examined the potential involvement of opioid receptors in depolarization-induced LTD because previous studies have identified a role for opioid mediated regulation of MF-CA3 transmission (Salin et al., 1995; Williams and Johnston 1996). In the presence of the general opioid receptor antagonist naloxone $(20 \mu \mathrm{M})$, depolarization of CA3 neurons for 5 min produced LTD that was indistinguishable from control: EPSC amplitude was $53 \pm 12 \%$ of control $15 \mathrm{~min}$ after the induction protocol $(n=4 ; p=0.03)$ (Fig. 2E). Finally, to determine whether intracellular $\mathrm{Ca}^{2+}$ was required for depolarization-induced LTD at MF-CA3 synapses, we included the intracellular $\mathrm{Ca}^{2+}$ chelator BAPTA $(30 \mathrm{~mm})$ in the recording pipette. After establishing the whole-cell configuration, we waited $\sim 20$ min to ensure adequate perfusion of BAPTA into the dendritic compartment before applying the LTD induction protocol. In the presence of BAPTA, depolarization did not significantly reduce EPSC amplitude $(93.1 \pm 2.1 \%$ of control; $n=6 ; p=0.07$ ) (Fig. $2 D, E$ ). In the absence of BAPTA LTD was still induced after $20 \mathrm{~min}$ of whole-cell recording $(47.4 \pm 2.1 \% ; n=3 ; p=0.002)$, excluding the possibility of washout of LTD. These results demonstrate that elevation of postsynaptic $\mathrm{Ca}^{2+}$ is necessary for LTD induction.
A
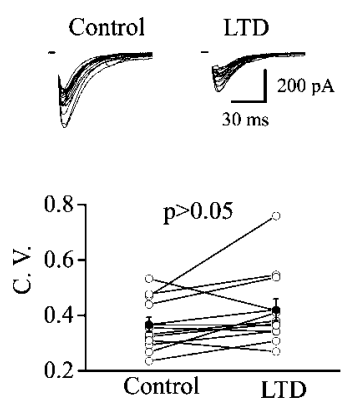

C

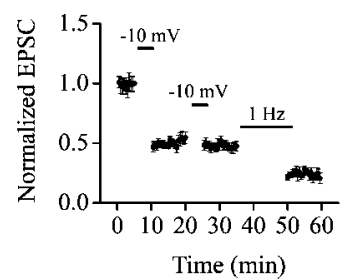

B


$\mathrm{D}$



Figure 4. Expression of depolarization-induced LTD at MF-CA3 synapses is postsynaptic. $A$, Lack of change in CV (SD/mean) before and after LTD induction. Top panel shows the consecutive 15 EPSCs before (left) and after (right) LTD induction. Individual experiments are indicated by open circles. Mean data are indicated by the closed circles. B, PPR evoked by two stimuli at an interval of 50 msec was not altered after the induction of LTD. Top left, EPSCs evoked by two stimuli before (thin) and after (thick) LTD induction. Top right, EPSCs before and after LTD induction were scaled to show the lack of difference in PPR. Individual experiments are indicated by open circles. Mean data are indicated by the closed circles. C, Depolarization-induced LTD did not occlude the $1 \mathrm{~Hz}$-induced LTD at MF-CA3 synapses. D, Similarly, the expression of 1 $\mathrm{Hz}$-induced LTD did not occlude depolarization-induced LTD at MF-CA3 synapses.

\section{Postsynaptic expression of LTD at MF-CA3 synapses}

We used three indicators to probe whether the expression of depolarization-induced LTD at MF-CA3 synapses was presynaptic or postsynaptic in origin. First, we calculated the CV (SD/ mean) before and after the induction of LTD (Fig. $4 A$ ). Although changes in $\mathrm{CV}$ do not unequivocally reflect a presynaptic mechanism (Silver et al., 1998), this parameter is widely used to evaluate changes in presynaptic transmitter release (Malinow and Tsien, 1990; McAllister and Stevens, 2000; Zucker and Regehr, 2002). The CV was not significantly changed after LTD induction (control, $0.37 \pm 0.03 ; \mathrm{LTD}, 0.42 \pm 0.04 ; n=12 ; p=0.09$ ) suggesting that the expression of LTD is not presynaptic. Second, we calculated the paired-pulse ratio (PPR) before and after LTD induction (Fig. $4 B$ ). The PPR was unchanged after LTD induction (control, $1.62 \pm 0.05 ; \mathrm{LTD}, 1.62 \pm 0.04 ; n=10 ; p=0.99$ ), again suggesting that the expression locus is not presynaptic. Third, we tested whether the expression of conventional lowfrequency stimulation ( $1 \mathrm{~Hz}$ for $15 \mathrm{~min}$ )-induced LTD and depolarization-induced LTD were related by sequentially applying both induction protocols. If depolarization-induced LTD shares the same presynaptic expression mechanism as lowfrequency stimulation-induced LTD (Tzounopoulos et al., 1998), we would expect one form of LTD to occlude the other. In each experiment, we applied the induction protocol for the first form of LTD twice to saturate expression before applying the subsequent induction protocol. The induction of low-frequencyinduced LTD was not occluded by previous expression of depolarization-induced LTD, and vice versa, suggesting that these two forms of LTD had different expression mechanisms (Fig. 4C,D). Taken together, the above three lines of evidence 
A
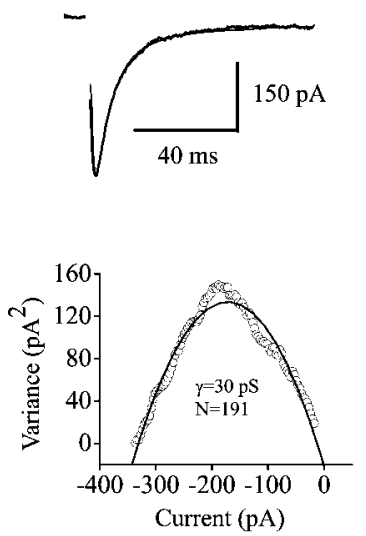

C



B
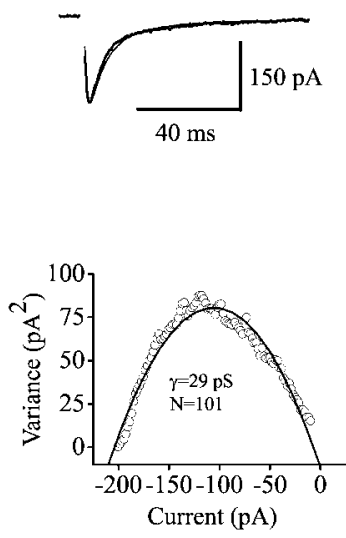

$\mathrm{D}$



Figure 5. Peak-scaled nonstationary variance analysis shows that depolarization-induced LTD correlates with a reduction in AMPAR number without a change in AMPAR conductance. $A$, Top, Average of 40 EPSCs before the induction of LTD was scaled to the peak of a single EPSC to calculate the variance. Bottom, Plot of variance versus current to calculate the conductance $(\gamma=30 \mathrm{pS})$ and number $(N=191)$ of postsynaptic AMPARs. $B$, Top, Average of 40 EPSCs from the same cell after the induction of LTD was scaled to the peak of a single EPSC to calculate the variance. Bottom, Variance and current relationship from the same cell after the induction of LTD. Note that the conductance was unchanged ( $\gamma=29 \mathrm{pS}$ ) but that the number of AMPARs was significantly reduced $(N=101)$. C, Summarized data from six neurons to show the lack of change in single-channel conductance after the induction of LTD $(n=6 ; p>0.05)$. D, In contrast, the number of the AMPARs was significantly reduced after LTD induction $(n=6$; $p<0.01)$.

suggest that the expression locus of depolarization-induced LTD is postsynaptic.

Postsynaptic LTD expression could result from a decrease in single-channel conductance $(\gamma)$ or open probability of AMPARs or a reduction in the number of available postsynaptic AMPARs. To differentiate among these possibilities, we used peak-scaled nonstationary variance analysis (Traynelis et al., 1993; Traynelis and Jaramillo, 1998; Benke et al., 1998; Lei and McBain, 2002). Because variations in amplitude will contaminate the estimate of variance attributable to channel closings, the individual events have to be scaled such that their peak amplitude equals the average peak amplitude. Therefore, peak-scaled variance analysis yields estimates of the single-channel conductance and the number of open channels without being able to resolve the open probability. Using this analysis we probed whether LTD was related to a reduction in single channel conductance or postsynaptic AMPAR number or both.

After LTD induction, AMPAR single-channel conductance was not significantly altered (control, $25.7 \pm 3.3 \mathrm{pS}$; LTD, $21.5 \pm$ $2.8 \mathrm{pS} ; n=6 ; p=0.20$ ) (Fig. $5 A-C$ ). In contrast, the number of the AMPARs on the postsynaptic membrane was significantly reduced after LTD induction (control, $196.3 \pm 7.8$; LTD, $106.3 \pm$ $13.9 ; n=6 ; p=0.0004$ ) (Fig. 5D). These results suggest that depolarization-induced LTD is attributable to a reduction in the number of postsynaptic AMPARs.

L-type $\mathrm{Ca}^{2+}$ channels are required for the induction of LTD In cultured hippocampal neurons AMPAR internalization relies, at least in part, on the activation of VGCCs (Lin et al., 2000). Because postsynaptic depolarization should activate VGCCs and depolarization-induced LTD relies on an increase in postsynaptic $\mathrm{Ca}^{2+}$, we next examined the role of VGCCs in the induction of LTD at MF-CA3 synapses using the VGCC antagonists $\omega$-conotoxin GVIA and nifedipine. Bath application of the $\mathrm{N}$-type $\mathrm{Ca}^{2+}$ channel blocker $\omega$-conotoxin GVIA $(0.5 \mu \mathrm{M})$ inhibited basal synaptic transmission to $44.9 \pm 2.9 \%$ of control $(n=5$; $p=0.00005)$, consistent with the known role of N-type $\mathrm{Ca}^{2+}$ channels in presynaptic release at MF-CA3 synapses (Castillo et al., 1994) (Fig. 6A,F). However, after inhibition of N-type $\mathrm{Ca}^{2+}$ channels, EPSCs of stable amplitude were recorded, and postsynaptic depolarization to $-10 \mathrm{mV}$ for $5 \mathrm{~min}$ induced further depression that remained for the duration of the recording (EPSCs were $43.5 \pm 4.7 \%$ of control $20 \mathrm{~min}$ after induction protocol; $n=$ $5 ; p=0.0003)($ Fig. $6 A, F)$. Thus, $\mathrm{N}$-type $\mathrm{Ca}^{2+}$ channel activation does not play a role in depolarization-induced LTD. In contrast, inhibition of L-type $\mathrm{Ca}^{2+}$ channels with bath application of nifedipine $(20 \mu \mathrm{M})$ did not produce any consistent changes in basal synaptic transmission but completely blocked the induction of LTD by postsynaptic depolarization: on average EPSC amplitude was $94.6 \pm 5.6 \%$ of control $20 \mathrm{~min}$ after the induction protocol $(n=11 ; p=0.36)$ (Fig. $6 B, F)$. Similar block of depolarizationinduced LTD by nifedipine was observed when experiments were repeated at $30-34^{\circ} \mathrm{C}(95.8 \pm 8.5 \%$ of control; $p=0.89 ; n=3$; data not shown).

To corroborate that membrane depolarization induces intracellular $\mathrm{Ca}^{2+}$ elevation via the activation of L-type $\mathrm{Ca}^{2+}$ channels, we combined whole-cell recording with $\mathrm{Ca}^{2+}$ imaging to measure changes in intracellular $\mathrm{Ca}^{2+}$ concentration in response to membrane depolarization at two different locations of dendrites of CA3 pyramidal neurons (Fig. $6 C, D$ ): the proximal portion of dendrites where mossy fibers arrive and the distal dendrites where recurrent collateral fibers contact (Brown and Johnston, 1983). Depolarization from -60 to $-10 \mathrm{mV}$ increased intracellular $\mathrm{Ca}^{2+}\left(\left[\mathrm{Ca}^{2+}\right]_{\mathrm{i}}\right)$ at both proximal and distal portions of dendrites (Fig. $6 \mathrm{C}$ ). The peak change of $\left[\mathrm{Ca}^{2+}\right]_{\mathrm{i}}$ induced by membrane depolarization was significantly higher in the proximal dendrites $(101.3 \pm 9.9 \% \Delta F / F ; n=7)$ than that in the distal dendrites (47.6 $\pm 10.1 \% \Delta F / F ; n=7 ; p<0.05)$. The difference was primarily attributable to the activation of L-type $\mathrm{Ca}^{2+}$ channels because nifedipine inhibited $\left[\mathrm{Ca}^{2+}\right]_{\mathrm{i}}$ elevation in proximal dendrites (control, $99.3 \pm 17.3 \% \Delta F / F$; nifedipine, $54.5 \pm 16.5 \%$ $\Delta F / F ; n=4 ; p<0.05)$ without significantly inhibiting the elevation of $\left[\mathrm{Ca}^{2+}\right]_{\mathrm{i}}$ at distal dendrites (control, $60.5 \pm 17.5 \% \Delta \mathrm{F} / \mathrm{F}$; nifedipine, $42.3 \pm 25.7 \% \Delta F / F ; p>0.05$ ) (Fig. $6 D$ ). Taken together these results suggest that activation of L-type $\mathrm{Ca}^{2+}$ channels at proximal dendrites of CA3 neurons where MFs terminate increases $\left[\mathrm{Ca}^{2+}\right]_{\mathrm{i}}$ to produce LTD.

A role for inositol 1,4,5-trisphosphate-sensitive intracellular $\mathrm{Ca}^{2+}$ stores in depolarization-induced LTD

$\mathrm{Ca}^{2+}$ signals mediated by VGCC activation are frequently amplified by $\mathrm{Ca}^{2+}$ induced $\mathrm{Ca}^{2+}$ release from intracellular stores (CICR). Because release of $\mathrm{Ca}^{2+}$ from intracellular stores has previously been implicated in synaptic plasticity (Wang et al., 1997; Emptage et al., 1999; Futatsugi et al., 1999; Nishiyama et al., 2000), our final series of experiments addressed the potential involvement of CICR in depolarization-induced LTD of MFCA3 synaptic transmission. We first examined the effect of depleting intracellular $\mathrm{Ca}^{2+}$ stores by intracellularly applying the 
A

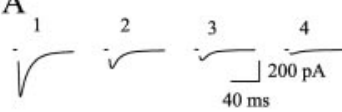

B
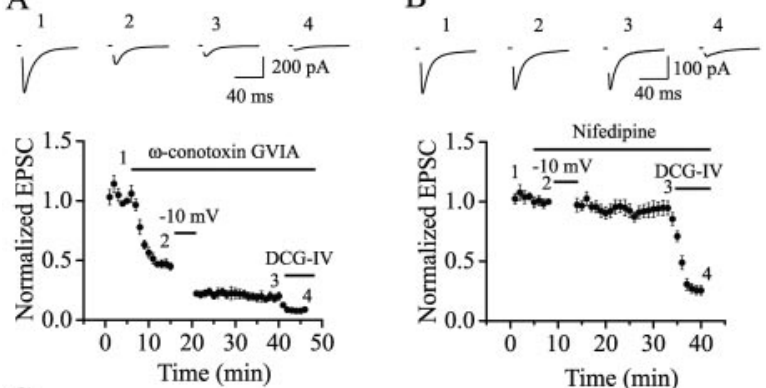

$\mathrm{C}$

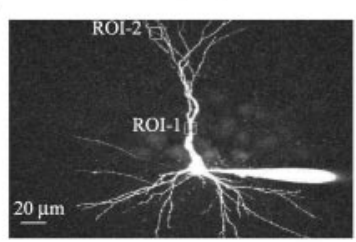

D

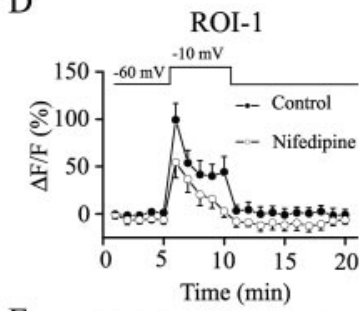

E



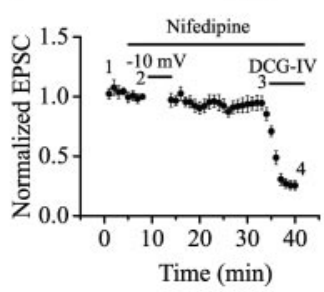


$\mathrm{F}$

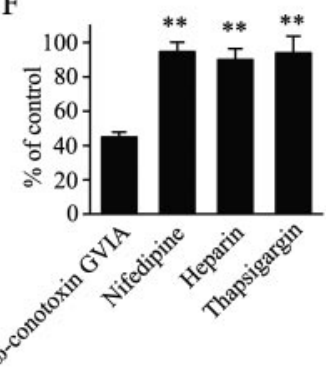

Figure 6. Involvement of $\mathrm{L}_{\text {-type }} \mathrm{Ca}^{2+}$ channels and $\operatorname{Ins}_{3}$-sensitive intracellular $\mathrm{Ca}^{2+}$ stores in depolarization-induced LTD at MF-CA3 synapses. A, Bath application of $\omega$-conotoxin GVIA $(0.5 \mu \mathrm{M})$ significantly reduced transmitter release but failed to inhibit the induction of LTD induced by membrane depolarization. EPSCs recorded at different time points in the figure are shown in the top panel. $B$, Bath application of nifedipine $(20 \mu \mathrm{m})$ blocked the induction of LTD. Top panel shows EPSCs recorded at different time points as indicated in the bottom plot. $C$, Membrane depolarization induces different intracellular $\mathrm{Ca}^{2+}$ elevations in the proximal and distal portions of the dendrites of CA3 pyramidal neurons. Left, Image of a CA3 pyramidal neuron dialyzed with $\mathrm{Ca}^{2+}$ indicator. $\mathrm{ROI}-1$ and $\mathrm{ROI}-2$ denote the proximal and distal portions of dendrites, respectively. Right, Enlargement of the proximal and distal parts of dendrites in response to membrane depolarization. Note more pronounced $\mathrm{Ca}^{2+}$ elevation in the proximal dendrite in response to membrane depolarization. D, Left, Bath application of nifedipine (40 $\mu \mathrm{m})$ significantly reduced elevation in intracellular $\mathrm{Ca}^{2+}$ in response to membrane depolarization in the proximal dendrite $(n=4 ; p<0.05)$. Right, Nifedipine failed to significantly reduce the increase in intracellular $\mathrm{Ca}^{2+}$ induced by membrane depolarization in the distal dendritic region $(p>0.05 ; n=4)$. E, Intracellular application of thapsigargin $(10 \mu \mathrm{m})$ blocked the induction of LTD. Top panel shows EPSCs recorded at different time points as indicated in the bottom plot for either thapsigargin-injected neurons (open circles) or interleaved controls (closed circles).F, Summary bar graph illustrating the magnitude of depolarization-induced LTD under the conditions indicated. Values are the average EPSC amplitudes recorded at 15 or 20 min after depolarization protocol expressed as a percentage of control values obtained just before initiating the depolarization protocol $\left({ }^{* *} p<0.01\right.$ compared with control LTD).

sarco(endo)plasmic reticulum $\mathrm{Ca}^{2+}$-ATPase (SERCA) pump inhibitor thapsigargin $(10 \mu \mathrm{M})$ through the recording pipette for at least 15 min before inducing LTD. In the presence of thapsigargin the depolarizing protocol failed to induce LTD of MF-CA3 transmission: at 15 min after depolarization, average EPSC amplitude

was $94 \pm 9.8 \%$ of control responses obtained just before depolarization $(n=5 ; p=0.58)$ compared with $52 \pm 9.4 \%$ in interleaved controls (Fig. $6 E, F$ ). Additionally, we attempted to induce LTD in CA3 cells loaded with low molecular weight heparin $(0.2$ $\mathrm{mg} / \mathrm{ml}$ ) to block release of inositol 1,4,5-trisphosphate $\left(\operatorname{InsP}_{3}\right)$ sensitive intracellular $\mathrm{Ca}^{2+}$ stores. Similar to thapsigargin, heparin prevented depolarization-induced LTD because EPSC amplitudes were $90 \pm 9.6 \%$ of control values $15 \mathrm{~min}$ after the induction protocol $(n=6 ; p=0.15$ ) (Fig. $6 F)$. These findings illustrate that $\mathrm{CICR}$ of $\mathrm{InsP}_{3}$-sensitive stores in $\mathrm{CA} 3$ neurons is required for depolarization-induced LTD of MF transmission.

\section{Discussion}

Our results demonstrate that membrane depolarization of CA3 pyramidal neurons induces distinct responses at $\mathrm{CF}-\mathrm{CA} 3$ and MF-CA3 synapses. At CF-CA3 synapses, membrane depolarization paired with presynaptic stimulation generates a heterogeneous response that ranges from LTP to LTD with several synapses showing no alteration of synaptic strength. However, the same induction paradigm applied at MF-CA3 synapses reliably induces LTD. This LTD of MF-CA3 synaptic transmission is independent of NMDARs, mGluR, cannabinoid and opioid receptors, or coincident synaptic activity, but requires a postsynaptic $\mathrm{Ca}^{2+}$ elevation through L-type $\mathrm{Ca}^{2+}$ channels and release from intracellular stores. Depolarization-induced LTD correlates with a reduction in AMPAR numbers without a change in AMPAR conductance. Finally, in single neurons, depolarization-induced LTD is expressed only at MF synapses and is absent at CF inputs.

Three distinct types of LTD have been previously observed at MF-CA3 synapses. (1) Low-frequency stimulation (1 Hz for 15 min) induces LTD in both juvenile and adult animals (Kobayashi et al., 1996; Domenici et al., 1998; Tzounopoulos et al., 1998). Induction of this type of LTD is dependent on neither NMDAR activity nor postsynaptic $\mathrm{Ca}^{2+}$, but requires presynaptic mGluR activity coupled to a decrease in cAMP-dependent PKA activity (Yokoi et al., 1996; Tzounopoulos et al., 1998). Both the induction and expression of this form of LTD are presynaptic in origin and are thought to be a reversal of the processes responsible for conventional mossy fiber LTP (Tzounopoulos et al., 1998). (2) High-frequency stimulation $(100 \mathrm{~Hz}, 1 \mathrm{sec})$ of mossy fibers in postnatal day 6-14 rats also induces LTD (Battistin and Cherubini, 1994; Domenici et al., 1998). Although the mechanism for this form of LTD is not clear, its induction requires neither NMDAR nor mGluR activities, but does depend on postsynaptic $\mathrm{Ca}^{2+}$ elevation (Domenici et al., 1998) and has an expression locus that is presynaptic (Domenici et al., 1998). (3) Intracellular "tetanization" of postsynaptic CA3 pyramidal neurons induces either LTD or LTP at MF-CA3 synapses in slices from 7- to 16-d-old rats (Berretta et al., 1999). This form of LTD also has a presynaptic expression locus and whether a synapse depresses or potentiates appears to depend widely on the initial release probability (Berretta et al., 1999).

In the present study, induction of depolarization-induced LTD required neither NMDAR nor mGluR activation, which is similar to the requirements for induction of $1 \mathrm{~Hz}$-induced LTD or the high-frequency-induced LTD in juvenile animals, respectively. However, depolarization-induced LTD is distinct from these forms of LTD in that its expression locus appears to be entirely postsynaptic. Consistent with this hypothesis is the observation that depolarization-induced LTD and $1 \mathrm{~Hz}$-induced LTD do not occlude each other, suggesting that they use distinct mechanisms. Although depolarization-induced LTD may share a 
similar induction mechanism to LTD induced by intracellular tetanization (postsynaptic depolarization), they appear to possess different expression loci. The expression of tetanizationinduced LTD is apparently presynaptic, but depolarizationinduced LTD has a postsynaptic expression locus. Furthermore, in the study by Berretta et al. (1999), tetanization induced either LTD or LTP, whereas in the present study direct postsynaptic depolarization consistently produced LTD. Based on the above evidence, we conclude that depolarization-induced LTD represents a novel form of LTD distinguishable from any of the above forms of LTD observed at MF-CA3 synapses.

$\mathrm{Ca}^{2+}$ influx through voltage-gated $\mathrm{Ca}^{2+}$ channels, especially L-type $\mathrm{Ca}^{2+}$ channels, has been implicated in synaptic plasticity at a variety of hippocampal synapses. In the CA1 region, L-type $\mathrm{Ca}^{2+}$ channels are involved in both LTP (Grover and Teyler, 1990; Aniksztejn and Ben-Ari, 1991; Kullmann et al., 1992; Huang and Malenka, 1993; Chen et al., 1998) and LTD induction (Christie et al., 1997; Normann et al., 2000; Wang et al., 2003). At MF-CA3 synapses, L-type channels are involved in the induction of "brief high-frequency" stimulation-induced LTP (Kapur et al., 1998). In dentate gyrus, induction of mGluR-dependent LTD requires membrane depolarization and $\mathrm{Ca}^{2+}$ influx via L-type $\mathrm{Ca}^{2+}$ channels (Wu et al., 2001). Moreover, L-type Ca ${ }^{+}$channels are involved in the induction of LTP in other areas including amygdala (Weisskopf et al., 1999; Bauer et al., 2002) and visual cortex (Aroniadou et al., 1993). The inductions of both LTP and LTD of retinocollicular synaptic transmission in the developing rat superior colliculus require L-type $\mathrm{Ca}^{2+}$ channel activation (Lo and Mize, 2002). All these results demonstrate that $\mathrm{Ca}^{2+}$ elevation mediated by L-type $\mathrm{Ca}^{2+}$ channels may serve as a reliable route for induction of LTP or LTD. Whether activation of L-type $\mathrm{Ca}^{2+}$ channels induces LTP or LTD may depend on the amount of $\mathrm{Ca}^{2+}$ influx and the types of intracellular targets activated.

Results from peak-scaled nonstationary variance analysis indicate that depolarization-induced LTD correlates with a reduction in the number of postsynaptic AMPARs, suggesting that $\mathrm{Ca}^{2+}$ through L-type $\mathrm{Ca}^{2+}$ channels induces AMPAR internalization through some as yet incompletely identified second messenger or messengers cascade. This result is consistent with the results of immunocytochemical experiments demonstrating that application of glutamate receptor agonists, including both NMDA and AMPA induce AMPAR endocytosis in cultured hippocampal neurons (Beattie et al., 2000; Ehlers, 2000; Lin et al., 2000). Intracellular $\mathrm{Ca}^{2+}$ is required for both NMDA- and AMPA-induced AMPAR endocytosis (Beattie et al., 2000). For NMDA-induced AMPAR internalization, $\mathrm{Ca}^{2+}$ entry is mediated by NMDARs, whereas AMPA-induced AMPAR endocytosis is triggered by VGCCs (Beattie et al., 2000; Lin et al., 2000), although the conformational changes of AMPARs induced by binding of AMPA to its receptors are also implicated (Lin et al., 2000). Of particular interest, application of NMDA and AMPA induce spatial differences in AMPAR internalization in cultured hippocampal neurons (Beattie et al., 2000). NMDA-induced AMPAR endocytosis is primarily observed in the more distal portion of dendrites, whereas AMPA-induced internalization, at least partially mediated by activation of VGCCs, is primarily restricted to the soma and proximal dendrites (Beattie et al., 2000). This spatially restricted pattern of AMPAR internalization induced by $\mathrm{Ca}^{2+}$ entry through NMDARs and $\mathrm{Ca}^{2+}$ channels is consistent with the selective innervation patterns of mossy fibers and recurrent collateral fibers on CA3 pyramidal neurons. Mossy fiber inputs are both anatomically and electrotonically closer to the soma than the recurrent collateral inputs, which are made onto the more distal dendrites of CA3 pyramidal neurons (Brown and Johnston, 1983). L-type $\mathrm{Ca}^{2+}$ channels are selectively located in the proximal portion of CA3 pyramidal neuron dendrites (Westenbroek et al., 1990; Hell et al., 1993; Elliott et al., 1995) where mossy fiber synapses form (Brown and Johnston, 1983), whereas NMDAR density is low in this area (Monaghan and Cotman, 1985; Jonas et al., 1993; Siegel et al., 1994; Weisskopf and Nicoll, 1995; Watanabe et al., 1998). Consistent with this anatomical scenario, postsynaptic depolarization activates L-type $\mathrm{Ca}^{2+}$ channels to induce AMPAR internalization (LTD) at proximal MF-CA3 synapses, whereas membrane depolarization paired with presynaptic stimulation opens NMDARs at distal CF-CA3 synapses to induce AMPAR endocytosis (LTD) or exocytosis (LTP) (Montgomery et al., 2001; Montgomery and Madison, 2002).

Although it is not entirely clear what second messenger or messengers couple $\mathrm{Ca}^{2+}$ entry through L-type $\mathrm{Ca}^{2+}$ channels to AMPAR internalization, block of depolarization-induced LTD by intracellular application of thapsigargin and heparin define a role for intracellular $\mathrm{Ca}^{2+}$ stores in the phenomenon. A likely candidate acting downstream of the rise in intracellular $\mathrm{Ca}^{2+}$ is the calcium-dependent protein phosphatase calcineurin. Activation of calcineurin after release of $\mathrm{Ca}^{2+}$ from InsP $\mathrm{P}_{3}$-sensitive intracellular $\mathrm{Ca}^{2+}$ stores appears to be responsible for dopamineand serotonin-mediated inhibition of VGCCs in striatal and cortical neurons, respectively (Hernandez-Lopez et al., 2000; Day et al., 2002). Additionally, in retinal amacrine cells, release of InsP $_{3}$ sensitive $\mathrm{Ca}^{2+}$ stores is reported to depress $\mathrm{GABA}_{\mathrm{A}}$ receptormediated currents via activation of calcineurin (Vigh and Lasater, 2003). Furthermore, a great deal of evidence implicates calcineurin as a key mediator of AMPAR endocytosis. At Schaffer collateral-CA1 pyramidal neuron synapses, calcineurin activity is required for NMDAR-dependent LTD (Lisman, 1989; Mulkey et al., 1993, 1994), a process considered to be mediated by AMPA receptor internalization (for review, see Malinow and Malenka, 2002). Moreover, the endocytosis of AMPARs after treatment of cultured cells with glutamate receptor agonists or insulin also relies on calcineurin activity (Beattie et al., 2000; Lin et al., 2000). Protein phosphatase 1 (PP1) has also been demonstrated to play an essential role in regulated AMPAR endocytosis (Ehlers, 2000; but see Beattie et al., 2000; Lin et al., 2000) and NMDARdependent LTD (Mulkey et al., 1993; Morishita et al., 2001), making PP1 another plausible candidate. Alternatively, the link from increased $\mathrm{Ca}^{2+}$ to AMPAR downregulation may not rely on a phosphatase activity at all. For instance, cerebellar LTD occurring through AMPAR internalization requires activation of the serine-threonine kinase PKC (Linden and Connor, 1991; Wang and Linden, 2000; Xia et al., 2000), and activation of PKC with phorbol esters can drive AMPAR internalization in cultured hippocampal neurons (Chung et al., 2000). Also, mGluR-triggered LTD at Schaffer collateral CA1 synapses is reported to be phosphatase-independent (Oliet et al., 1997). Given the large number of possibilities, further investigation will be required to determine whether depolarization-induced LTD shares downstream signaling elements common to other forms of LTD or uses a novel mechanism.

\section{References}

Alger BE (2002) Retrograde signaling in the regulation of synaptic transmission: focus on endocannabinoids. Prog Neurobiol 68:247-286.

Amaral DG, Dent JA (1981) Development of the mossy fibers of the dentate gyrus: I. A light and electron microscopic study of the mossy fibers and their expansions. J Comp Neurol 195:51-86. 
Aniksztejn L, Ben-Ari Y (1991) Novel form of long-term potentiation produced by a ${ }^{+}$channel blocker in the hippocampus. Nature 349:67-69.

Aroniadou VA, Maillis A, Stefanis CC (1993) Dihydropyridine-sensitive calcium channels are involved in the induction of $N$-methyl-D-aspartate receptor-independent long-term potentiation in visual cortex of adult rats. Neurosci Lett 151:77-80.

Auger C, Attwell D (2000) Fast removal of synaptic glutamate by postsynaptic transporters. Neuron 28:547-558.

Battistin T, Cherubini E (1994) Developmental shift from long-term depression to long-term potentiation at the mossy fibre synapses in the rat hippocampus. Eur J Neurosci 6:1750-1755.

Bauer EP, Schafe GE, LeDoux JE (2002) NMDA receptors and L-type voltage-gated calcium channels contribute to long-term potentiation and different components of fear memory formation in the lateral amygdala. J Neurosci 22:5239-5249.

Beattie EC, Carroll RC, Yu X, Morishita W, Yasuda H, von Zastrow M, Malenka RC (2000) Regulation of AMPA receptor endocytosis by a signaling mechanism shared with LTD. Nat Neurosci 3:1291-1300.

Benke TA, Luthi A, Isaac JT, Collingridge GL (1998) Modulation of AMPA receptor unitary conductance by synaptic activity. Nature 393:793-797.

Bergles DE, Jahr CE (1998) Glial contribution to glutamate uptake at Schaffer collateral-commissural synapses in the hippocampus. J Neurosci 18:7709-7716.

Berretta N, Rossokhin AV, Cherubini E, Astrelin AV, Voronin LL (1999) Long-term synaptic changes induced by intracellular tetanization of CA3 pyramidal neurons in hippocampal slices from juvenile rats. Neuroscience 93:469-477.

Bertrand S, Ng GY, Purisai MG, Wolfe SE, Severidt MW, Nouel D, Robitaille R, Low MJ, O’Neill GP, Metters K, Lacaille JC, Chronwall BM, Morris SJ (2001) The anticonvulsant, antihyperalgesic agent gabapentin is an agonist at brain gamma-aminobutyric acid type B receptors negatively coupled to voltage-dependent calcium channels. J Pharmacol Exp Ther 298:15-24.

Bortolotto ZA, Fitzjohn SM, Collongridge GL (1999) Roles of metabotropic glutamate receptors in LTP and LTD in the hippocampus. Curr Opin Neurobiol 9:299-304.

Brown TH, Johnston D (1983) Voltage-clamp analysis of mossy fiber synaptic input to hippocampal neurons. J Neurophysiol 50:487-507.

Carlson G, Wang Y, Alger BE (2002) Endocannabinoids facilitate the induction of LTP in the hippocampus. Nat Neurosci 5:723-724.

Castillo PE, Weisskopf MG, Nicoll RA (1994) The role of $\mathrm{Ca}^{2+}$ channels in hippocampal mossy fiber synaptic transmission and long-term potentiation. Neuron 12:261-269.

Castillo PE, Janz R, Sudhof TC, Tzounopoulos T, Malenka RC, Nicoll RA (1997) Rab3A is essential for mossy fibre long-term potentiation in the hippocampus. Nature 388:590-593.

Chen HX, Hanse E, Pananceau M, Gustafsson B (1998) Distinct expressions for synaptic potentiation induced by calcium through voltage-gated calcium and $N$-methyl-D-aspartate receptor channels in the hippocampal CA1 region. Neuroscience 86:415-422.

Chevaleyre V, Castillo PE (2003) Heterosynaptic LTD of hippocampal GABAergic synapses: a novel role of endocannabinoids in regulating excitability. Neuron 38:461-472.

Cho K, Bahir ZI (2002) Cooperation between mglu receptors: a depressing mechanism? Trends Neurosci 25:405-411.

Christie BR, Schexnayder LK, Johnston D (1997) Contribution of voltagegated $\mathrm{Ca}^{2+}$ channels to homosynaptic long-term depression in the CA1 region in vitro. J Neurophysiol 77:1651-1655.

Chung HJ, Xia J, Scannevin RH, Zhang X, Huganir RL (2000) Phosphorylation of the AMPA receptor subunit GluR2 differentially regulates its interaction with PDZ domain-containing proteins. J Neurosci 20:7258-7267.

Day M, Olson P, Platzer J, Striessnig J, Surmeier DJ (2002) Stimulation of $5-\mathrm{HT}_{2}$ receptors in prefrontal pyramidal neurons inhibits $\mathrm{Ca}_{\mathrm{v}} 1.2 \mathrm{~L}$-type $\mathrm{Ca}^{2+}$ currents via a PLC $\beta / \mathrm{IP} 3 /$ calcineurin signaling cascade. J Neurophysiol 87:2490-2504.

Debanne D, Gahwiler BH, Thompson SM (1998) Long-term synaptic plasticity between pairs of individual CA3 pyramidal cells in rat hippocampal slice cultures. J Physiol (Lond) 507:237-247.

Debanne D, Gahwiler BH, Thompson SM (1999) Heterogeneity of synaptic plasticity at unitary CA3-CA1 and CA3-CA3 connections in rat hippocampal slice cultures. J Neurosci 19:10664-10671.
Domenici MR, Berretta N, Cherubini E (1998) Two distinct forms of longterm depression coexist at the mossy fiber-CA3 synapse in the hippocampus during development. Proc Natl Acad Sci USA 95:8310-8315.

Ehlers MD (2000) Reinsertion or degradation of AMPA receptors determined by activity-dependent endocytic sorting. Neuron 28:511-525.

Elliott EM, Malouf AT, Catterall WA (1995) Role of calcium channel subtypes in calcium transients in hippocampal CA3 neurons. J Neurosci 15:6433-6444.

Emptage N, Bliss TV, Fine A (1999) Single synaptic events evoke NMDA receptor-mediated release of calcium from intracellular stores in hippocampal dendritic spines. Neuron 22:115-124.

Futatsugi A, Kato K, Ogura H, Li ST, Nagata E, Kuwajima G, Tanaka K, Itohara S, Mikoshiba K (1999) Facilitation of NMDAR-independent LTP and spatial learning in mutant mice lacking ryanodine receptor type 3. Neuron 24:701-713.

Gasparini S, Saviane C, Veronin L, Cherubini E (2000) Silent synapses in the developing hippocampus: lack of functional AMPA receptors or low probability of glutamate release? Proc Natl Acad Sci USA 97:9741-9746.

Gerdeman GL, Ronesi J, Lovinger DM (2002) Postsynaptic endocannabinoid release is critical to long-term depression in the striatum. Nat Neurosci 5:446-451.

Grover LM, Teyler TJ (1990) Two components of long-term potentiation induced by different patterns of afferent activation. Nature 347:477-479.

Hardingham NR, Larkman AU (1998) The reliability of excitatory synaptic transmission in slices of rat visual cortex in vitro is temperature dependent. J Physiol (Lond) 507:249-256.

Harris EW, Cotman CW (1986) Long-term potentiation of guinea pig mossy fiber responses is not blocked by $N$-methyl-D-aspartate antagonists. Neurosci Lett 70:132-137.

Hell JW, Westenbroek RE, Warner C, Ahlijanian MK, Prystay W, Gilbert MM, Snutch TP, Catterall WA (1993) Identification and differential subcellular localization of the neuronal class $C$ and class D L-type calcium channel alphal subunits. J Cell Biol 123:949-962.

Henze DA, Urban NN, Barrionuevo G (2000) The multifarious hippocampal mossy fiber pathway: a review. Neuroscience 98:407-427.

Hernandez-Lopez S, Tkatch T, Perez-Garci E, Galarraga E, Bargas J, Hamm $\mathrm{H}$, Surmeier DJ (2000) $\mathrm{D}_{2}$ dopamine receptors in striatal medium spiny neurons reduce L-type $\mathrm{Ca}^{2+}$ currents and excitability via a novel PLC $\beta 1$ $\mathrm{IP}_{3}$-calcineurin-signaling cascade. J Neurosci 20:8987-8995.

Huang YY, Malenka RC (1993) Examination of TEA-induced synaptic enhancement in area CA1 of the hippocampus: the role of voltagedependent $\mathrm{Ca}^{2+}$ channels in the induction of LTP. J Neurosci 13:568-576.

Jonas P, Major G, Sakmann B (1993) Quantal components of unitary EPSCs at the mossy fibre synapse on CA3 pyramidal cells of rat hippocampus. J Physiol (Lond) 472:615-663.

Kapur A, Yeckel MF, Gray R, Johnston D (1998) L-Type calcium channels are required for one form of hippocampal mossy fiber LTP. J Neurophysiol 79:2181-2190.

Kobayashi K, Manabe T, Takahashi T (1996) Presynaptic long-term depression at the hippocampal mossy fiber-CA3 synapse. Science 273:648-650.

Kullmann DM, Perkel DJ, Manabe T, Nicoll RA (1992) $\mathrm{Ca}^{2+}$ entry via postsynaptic voltage-sensitive $\mathrm{Ca}^{2+}$ channels can transiently potentiate excitatory synaptic transmission in the hippocampus. Neuron 9:1175-1183.

Lei S, McBain CJ (2002) Distinct NMDA receptors provide differential modes of transmission at mossy fiber-interneuron synapses. Neuron 33:921-933.

Lei S, McBain CJ (2003) GABA(B) receptor modulation of excitatory and inhibitory synaptic transmission onto rat CA3 hippocampal interneurons. J Physiol (Lond) 546:439-453.

Lin JW, Ju W, Foster K, Lee SH, Ahmadian G, Wyszynski M, Wang YT, Sheng M (2000) Distinct molecular mechanisms and divergent endocytotic pathways of AMPA receptor internalization. Nat Neurosci 3:1282-1290.

Linden DJ, Connor JA (1991) Participation of postsynaptic PKC in cerebellar long-term depression in culture. Science 254:1656-1659.

Lisman J (1989) A mechanism for the Hebb and the anti-Hebb processes underlying learning and memory. Proc Natl Acad Sci USA 86:9574-9578.

Lo FS, Mize RR (2002) Properties of LTD and LTP of retinocollicular synaptic transmission in the developing rat superior colliculus. Eur J Neurosci 15:1421-1432.

Lopez-Garcia JC, Arancio O, Kandel ER, Baranes D (1996) A presynaptic 
locus for long-term potentiation of elementary synaptic transmission at mossy fiber synapses in culture. Proc Natl Acad Sci USA 93:4712-4717.

Malinow R, Malenka RC (2002) AMPA receptor trafficking and synaptic plasticity. Annu Rev Neurosci 25:103-126.

Malinow R, Tsien RW (1990) Presynaptic enhancement shown by wholecell recordings of long-term potentiation in hippocampal slices. Nature 346:177-180.

McAllister AK, Stevens CF (2000) Nonsaturation of AMPA and NMDA receptors at hippocampal synapses. Proc Natl Acad Sci USA 97:6173-6178.

Mellor J, Nicoll RA (2001) Hippocampal mossy fiber LTP is independent of postsynaptic calcium. Nat Neurosci 4:125-126.

Misner DL, Sullivan JM (1999) Mechanism of cannabinoid effects on longterm potentiation and depression in hippocampal CA1 neurons. J Neurosci 19:6795-6805.

Monaghan DT, Cotman CW (1985) Distribution of N-methyl-D-aspartatesensitive L- $[3 \mathrm{H}]$ glutamate-binding sites in rat brain. J Neurosci 5:2909-2919.

Montgomery JM, Madison DV (2002) State-dependent heterogeneity in synaptic depression between pyramidal cell pairs. Neuron 33:765-777.

Montgomery JM, Pavlidis P, Madison DV (2001) Pair recordings reveal allsilent synaptic connections and the postsynaptic expression of long-term potentiation. Neuron 29:691-701.

Morishita W, Connor JH, Xia H, Quinlan EM, Shenolikar S, Malenka RC (2001) Regulation of synaptic strength by protein phosphatase 1 . Neuron 32:1133-1148.

Mulkey RM, Herron CE, Malenka RC (1993) An essential role for protein phosphatases in hippocampal long-term depression. Science 261:1051-1055.

Mulkey RM, Endo S, Shenolikar S, Malenka RC (1994) Involvement of a calcineurin/inhibitor-1 phosphatase cascade in hippocampal long-term depression. Nature 369:486-488.

Nicoll RA, Malenka RC (1995) Contrasting properties of two forms of longterm potentiation in the hippocampus. Nature 377:115-118.

Nishiyama M, Hong K, Mikoshiba K, Poo MM, Kato K (2000) Calcium stores regulate the polarity and input specificity of synaptic modification. Nature 408:584-588.

Normann C, Peckys D, Schulze CH, Walden J, Jonas P, Bischofberger J (2000) Associative long-term depression in the hippocampus is dependent on postsynaptic N-type $\mathrm{Ca}^{2+}$ channels. J Neurosci 20:8290-8297.

Oliet SH, Malenka RC, Nicoll RA (1997) Two distinct forms of long-term depression coexist in CA1 hippocampal pyramidal cells. Neuron 18:969-982.

Salin PA, Weisskopf MG, Nicoll RA (1995) A comparison of the role of dynorphin in the hippocampal mossy fiber pathway in guinea pig and rat. J Neurosci 15:6939-6945.

Siegel SJ, Brose N, Janssen WG, Gasic GP, Jahn R, Heinemann SF, Morrison $\mathrm{JH}$ (1994) Regional, cellular, and ultrastructural distribution of $\mathrm{N}$-methyl-D-aspartate receptor subunit 1 in monkey hippocampus. Proc Natl Acad Sci USA 91:564-568.

Silver RA, Momiyama A, Cull-Candy SG (1998) Locus of frequencydependent depression identified with multiple-probability fluctuation analysis at rat climbing fibre-Purkinje cell synapses. J Physiol (Lond) 510:881-902.

Toth K, Suares G, Lawrence JJ, Philips-Tansey E, McBain CJ (2000) Differential mechanisms of transmission at three types of mossy fiber synapse. J Neurosci 20:8279-8289.

Traynelis SF, Jaramillo F (1998) Getting the most out of noise in the central nervous system. Trends Neurosci 21:137-145.
Traynelis SF, Silver RA, Cull-Candy SG (1993) Estimated conductance of glutamate receptor channels activated during EPSCs at the cerebellar mossy fiber-granule cell synapse. Neuron:279-289.

Tzounopoulos T, Janz R, Sudhof TC, Nicoll RA, Malenka RC (1998) A role for cAMP in long-term depression at hippocampal mossy fiber synapses. Neuron 21:837-845.

Vigh J, Lasater (2003) Intracellular calcium release resulting from mGluR1 receptor activation modulates $\mathrm{GABA}_{\mathrm{A}}$ currents in wide-field retinal amacrine cells: a study with caffeine. Eur J Neurosci 17:2237-2248.

Wang Y, Rowan MJ, Anwyl R (1997) Induction of LTD in the dentate gyrus in vitro is NMDA receptor independent, but dependent on $\mathrm{Ca}^{2+}$ influx via low-voltage-activated $\mathrm{Ca}^{2+}$ channels and release of $\mathrm{Ca}^{2+}$ from intracellular stores. J Neurophysiol 77:812-825.

Wang YT, Linden DJ (2000) Expression of cerebellar long-term depression requires postsynaptic clathrin-mediated endocytosis. Neuron 25:635-647.

Wang Z, Xu NL, Wu CP, Duan S, Poo MM (2003) Bidirectional changes in spatial dendritic integration accompanying long-term synaptic modifications. Neuron 37:463-472.

Watanabe M, Fukaya M, Sakimura K, Manabe T, Mishina M, Inoue Y (1998) Selective scarcity of NMDA receptor channel subunits in the stratum lucidum (mossy fibre-recipient layer) of the mouse hippocampal CA3 subfield. Eur J Neurosci 10:478-487.

Weisskopf MG, Bauer EP, LeDoux JE (1999) L-type voltage-gated calcium channels mediate NMDA-independent associative long-term potentiation at thalamic input synapses to the amygdala. J Neurosci 19:10512-10519.

Weisskopf MG, Nicoll RA (1995) Presynaptic changes during mossy fibre LTP revealed by NMDA receptor-mediated synaptic responses. Nature 376:256-259.

Westenbroek RE, Ahlijanian MK, Catterall WA (1990) Clustering of L-type $\mathrm{Ca}^{2+}$ channels at the base of major dendrites in hippocampal pyramidal neurons. Nature 347:281-284.

Williams SH, Johnston D (1996) Actions of endogenous opioids on NMDA receptor-independent long-term potentiation in area CA3 of the hippocampus. J Neurosci 16:3652-3660.

Wu J, Rush A, Rowan MJ, Anwyl R (2001) NMDA receptor- and metabotropic glutamate receptor-dependent synaptic plasticity induced by high frequency stimulation in the rat dentate gyrus in vitro. J Physiol (Lond) 533:745-755.

Xia J, Chung HJ, Wihler C, Huganir RL, Linden DJ (2000) Cerebellar longterm depression requires PKC-regulated interactions between GluR2/3 and PDZ domain-containing proteins. Neuron 28:499-510.

Xiang Z, Greenwood AC, Kairiss EW, Brown TH (1994) Quantal mechanism of long-term potentiation in hippocampal mossy-fiber synapses. J Neurophysiol 71:2552-2556.

Yeckel MF, Kapur A, Johnston D (1999) Multiple forms of LTP in hippocampal CA3 neurons use a common postsynaptic mechanism. Nat Neurosci 2:625-633.

Yokoi M, Kobayashi K, Manabe T, Takahashi T, Sakaguchi I, Katsuura G, Shigemoto R, Ohishi H, Nomura S, Nakamura K, Nakao K, Katsuki M, Nakanishi S (1996) Impairment of hippocampal mossy fiber LTD in mice lacking mGluR2. Science 273:645-647.

Zalutsky RA, Nicoll RA (1990) Comparison of two forms of long-term potentiation in single hippocampal neurons. Science 248:1619-1624.

Zucker RS, Regehr WG (2002) Short-term synaptic plasticity. Annu Rev Physiol 64:355-405. 